\title{
Pemberian Penguatan Verbal dan Non-verbal untuk Meningkatkan Hasil Belajar Siswa dalam Pembelajaran Kepahlawanan dan Patriotisme
}

\section{Siti Yunanik}

SDN 2 Sandik, Batulayar, Lombok Barat, Jl. Pariwisata, Sandik, Batu Layar, 83351, Indonesia

Email: sitiyunanik19621231@yahoo.com

$\begin{array}{ll}\text { ARTICLE INFO } & \text { ABSTRACT } \\ \begin{array}{l}\text { Article history } \\ \text { Received: March } 2019\end{array} & \text { [Title: The Provision of Verbal and Non-verbal Reinforcement to Improve } \\ \text { Revised: April } 2019 & \text { Student Learning Achievement in Heroism and Patriotism Subject Matter]. The } \\ \text { Accepted: May } 2019 & \text { purpose of this study is to improve student learning achievement on the heroic and } \\ \text { Published: June 2019 } & \begin{array}{l}\text { patriotism figures subject matter through the provision of verbal and non-verbal } \\ \text { reinforcement. This research is a class action research (CAR) with the subject of the } \\ \text { research were class IV students in semester } 1 \text { of SDN } 2 \text { Sandik, amounting to } 28\end{array} \\ \text { Keywords } & \text { students. Student learning achievement data were collected using test instruments and } \\ \text { verbal and non-verbal } & \text { analyzed descriptively-qualitatively. The results showed that the student learning } \\ \text { reinforcement; } & \text { achievement in the first cycle was in the medium category (mean = 5.50) increased in } \\ \text { student learning } & \text { the second cycle (mean = 8.25) with the good category. The implementation of learning } \\ \text { achievement } & \text { has also increased in each cycle. Based on the results of the study it can be concluded } \\ & \text { that the provision of verbal and non-verbal reinforcement can improve student learning } \\ \text { achievement on the heroic and patriotism figures subject matter at SDN } 2 \text { Sandik. }\end{array}$

\section{INFO ARTIKEL}

Sejarah Artikel

Dikirim: Maret 2019

Direvisi: April 2019

Diterima: Mei 2019

Dipublikasi: Juni 2019

\section{Kata kunci} penguatan verbal dan non-verbal;

hasil belajar siswa

\begin{abstract}
ABSTRAK
Tujuan penelitian ini adalah meningkatkan hasil belajar siswa dalam pembelajaran kepahlawanan dan patriotisme tokoh-tokoh di lingkungan anak melalui pemberian penguatan verbal dan non-verbal. Penelitian ini merupakan penelitian tindakan kelas (PTK) dengan subjek penelitian adalah siswa kelas IV semester 1 SDN 2 Sandik yang berjumlah 28 siswa. Data hasil belajar siswa dikumpulkan menggunakan instrumen tes dan dianalisis secara deskriptifkualitatif. Hasil penelitian menunjukkan hasil belajar siswa pada siklus I berkategori sedang (nilai rata-rata $=5,50$ ) meningkat pada siklus II (nilai ratarata $=8,25$ ) dengan kategori baik. Keterlaksanaan pembelajaran juga mengalami peningkatan pada setiap siklus. Berdasarkan hasil penelitian dapat disimpulkan bahwa pemberian penguatan verbal dan non-verbal dapat meningkatkan hasil belajar siswa dalam pembelajaran kepahlawanan dan patriotisme tokoh-tokoh di lingkungan anak di SDN 2 Sandik.
\end{abstract}

How to Cite this Article? Yunanik, S. (2019). Pemberian Penguatan Verbal dan Non-verbal untuk Meningkatkan Hasil Belajar Siswa dalam Pembelajaran Kepahlawanan dan Patriotisme. Jurnal Penelitian dan Pengkajian Ilmu Pendidikan: e-Saintika, 2(2), 98-104. 


\section{PENDAHULUAN}

Ilmu Pengetahuan Sosial (IPS) merupakan salah satu mata pelajaran yang diberikan mulai dari SD/MI/SDLB sampai SMP/MTs/SMPLB. IPS mengkaji seperangkat peristiwa, fakta, konsep, dan generalisasi yang berkaitan denganisu sosial. Pada jenjang SMP/MTs mata pelajaran IPS memuat materi Geografi, Sejarah, Sosiologi, dan Ekonomi. Melalui mata pelajaran IPS, peserta didik diarahkan untuk dapat menjadi warga negara Indonesia yang demokratis, dan bertanggung jawab, serta warga dunia yang cinta damai. Di masa yang akan datang peserta didik akan menghadapi tantangan berat karena kehidupan masyarakat global selalu mengalami perubahan setiap saat. Oleh karena itu mata pelajaran IPS dirancang untuk mengembangkan pengetahuan, pemahaman, dan kemampuan analisis terhadap kondisi social masyarakat dalam memasuki kehidupan bermasyarakat yang dinamis. Mata pelajaran IPS disusun secara sistematis, komprehensif, dan terpadu dalam proses pembelajaran menuju kedewasaan dan keberhasilan dalam kehidupan di masyarakat. Dengan pendekatan tersebut diharapkan peserta didik akan memperoleh pemahaman yang lebih luas dan mendalam pada bidang ilmu yang berkaitan (Andayani, 2009).

Lebih lanjut Farris dan Cooper (1994) menjelaskan tujuan mata pelajaran IPS yaitu agar peserta didik memiliki kemampuan (1) mengenal konsep-konsep yang berkaitan dengan kehidupan masyarakat dan lingkungannya, (2) memiliki kemampuan dasar untuk berpikir logis dan kritis, rasa ingin tahu, inkuiri, memecahkan masalah, dan keterampilan dalam kehidupan social, (3) memiliki komitmen dan kesadaran terhadap nilai-nilai sosial dan kemanusiaan, dan (4) memiliki kemampuan berkomunikasi, bekerjasama dan berkompetisi dalam masyarakat yang majemuk, di tingkat lokal, nasional, dan global.

Ilmu Pengetahuan Sosial (IPS) adalah salah satu bidang studi yang rumit, karena ruang lingkupnya sangat luas dan merupakan gabungan dari ilmu-ilmu sosial, seperti geografi, ekonomi, sejarah, sosiologi, dan antropologi. IPS memfokuskan perhatiannya pada peranan manusia dalam masyarakat terutama dalam situasi global saat ini. Pembelajaran suatu pelajaran akan bermakna bagi siswa apabila guru mengetahui tentang objek yang diajarkannya sehingga dapat mengajarkan materi tersebut dengan penuh dinamika dan inovasi dalam proses pembelajarannya.

Pendidikan Ilmu Pengetahuan Sosial (IPS) di SD harus memperhatikan kebutuhan anak yang berusia antara 6-12 tahun. Anak dalam kelompok usia 7-11 tahun menurut Piaget (1963) berada dalam perkembangan kemampuan intelektual/kognitif pada tingkat kongkrit operasional. Wetton dan Mallan (1998) menjelaskan anak memandang dunia dalam keseluruhan yang utuh, dan menganggap tahun yang akan datang sebagai waktu yang masih jauh. Anak pada umur tersebut hanya mempedulikan sekarang (kongkrit), dan bukan masa depan yang belum bisa dipahami (abstrak). Padahal bahan materi IPS penuh dengan pesan-pesan yang bersifat abstrak. Konsep-konsep seperti waktu, perubahan, kesinambungan (continuity), arah mata angin, lingkungan, ritual, akulturasi, kekuasaan, demokrasi, nilai, peranan, permintaan, atau kelangkaan adalah konsepkonsep abstrak yang dalam program studi IPS harus dibelajarkan kepada siswa SD. 
Berbagai cara dan teknik pembelajaran dikaji untuk memungkinkan konsepkonsep abstrak dapat dipahami anak (Sumantri, 2007). Bruner (1978) memberikan pemecahan berbentuk jembatan bailey untuk mengkongkritkan yang abstrak dengan enactive, iconic, dan symbolic melalui percontohan dengan gerak tubuh, gambar, bagan, peta, grafik, lambang, keterangan lanjut, atau elaborasi dalam katakata yang dapat dipahami siswa. Hal tersebut menyebabkan IPS SD bergerak dari yang kongkrit ke yang abstrak dengan mengikuti pola pendekatan lingkungan yang semakin meluas (expanding environment approach) dan pendekatan spiral berangkat dari yang mudah kepada yang sulit, dari yang sempit menjadi lebih luas, dari yang dekat ke yang jauh, dan seterusnya.

Guru sebagai praktisi melaksanakan kegiatan, dengan cara menggunakan strategi pengajaran konsep untuk membantu kelancaran pada setiap tindakan pembelajaran. Secara umum strategi mempunyai pengertian suatu garis-garis besar haluan untuk bertindak dalam usaha mencapai sasaran yang telah ditentukan. Dihubungkan dengan belajar mengajar, strategi bisa diartikan sebagai pola-pola umum kegiatan guru dan anak didik dalam mewujudkan kegiatan belajar mengajar untuk mencapai tujuan yang telah digariskan. Menurut Newman dan Logan (1971), strategi dasar dari setiap usaha akan mencakup keempat hal yaitu (1) Mengidentifikasi dan menetapkan spesifikasi dan kualifikasi hasil seperti apa yang harus dicapai dan menjadi sasaran usaha itu yang sesuai dengan aspirasi dan selera masyarakat, (2) Mempertimbangkan dan memilih jalan pendekatan utama manakah yang dipandang paling efektif guna mencapai sasaran tersebut, (3) Mempertimbangkan dan menetapkan langkah-langkah apa saja yang akan ditempuh untuk mencapai sasaran tersebut, dan (4) Mempertimbangkan dan menetapkan kriteria dan patokan ukuran yang harus dipergunakan untuk mengukur dan menilai taraf keberhasilan usaha tersebut.

Salah satu penguatan yang dapat diintegrasikan dalam strategi pembelajaran yang dapat digunakan dan relevan dengan pembelajaran IPS adalah penguatan verbal dan non-verbal. Menurut Sanjaya (2006); Barnawi dan Arifin (2012), penguatan verbal adalah penguatan yang diungkapkan dengan kata-kata, baik pujian dan penghargaan atau kata-kata koreksi, sedangkan penguatan non-verbal adalah penguatan yang diungkapkan melalui bahasa isyarat. Penguatan berpengaruh positif pada sikap siswa (Usman, 2013) dan seharusnya dioptimalkan guru dalam proses pembelajaran untuk meningkatkan hasil belajar siswa (Dimyati, 2003).

Penelitian ini bertujuan bertujuan untuk meningkatkan hasil belajar siswa dalam pembelajaran kepahlawanan agar pembelajaran bisa dipahami secara merata, meningkatkan proses belajar mengajar pada Mata Pelajaran IPS, meningkatkan pemahaman siswa dalam belajar dengan metode pemberian penguatan verbal dan non verbal. Hasil penelitian ini diharapkan dapat memberikan sumbangsih pengetahuan dalam rangka meningkatkan kualitas pembelajaran, memberikan kesan belajar IPS mudah dan menyenangkan serta dapat memberikan wawasan materi pembelajaran, serta dapat dijadikan rujukan atau bahan pembelajaran dalam upaya meningkatkan hasil belajar siswa. 


\section{METODE}

Penelitian ini merupakan penelitian tindakan kelas (PTK). Secara garis besar terdapat 4 tahapan yaitu (1) Menyusun rancangan tindakan (planning/perencanaan), dalam tahap ini peneliti menjelaskan tentang apa, mengapa, kapan, dimana, oleh siapa, dan bagaimana tindakan akan dilakukan. Penelitian tindakan yang ideal sebetulnya dilakukan secara berpasangan antara pihak yang melakukan tindakn dan pihak yang mengamati proses yang dijalankan, (2) Pelaksanaan Tindakan (acting), tahap ini merupakan implementasi atau penerapan isi rancangan, yaitu mengenakan tindakan di kelas, (3) Pengamatan (observing), yaitu kegiatan pengamatan yang dilakukan oleh pengamat. Dalam tahap ini, guru pelaksana mencatat sedikit demi sedikit apa yang terjadi agar memperoleh data yang akurat untuk perbaikan siklus berikutnya, (4) Refleksi (reflecting), merupakan kegiatan untuk mengemukakan kembali apa yang sudah dilakukan. Dalam tahap ini, guru berusaha untuk menemukan hal-hal yang sudah dirasakan memuaskan hati karena sudah sesuai dengan rancangan dan secar cermat mengenali hal-hal yang masih perlu diperbaiki (Arikunto, 2006).

\section{Subjek Penelitian}

Penelitian ini dilaksanakan di kelas IV SDN 2 Sandik Kec. Batulayar Kab. Lombok Barat, mulai tanggal 6 Agustus sampai dengan tanggal 20 Agustus 2018 dengan jumlah subjek 28 siswa yang terdiri dari 16 orang laki-laki dan 12 orang perempuan.

\section{Deskripsi Per-Siklus}

\section{Rencana Penelitian}

Berdasarkan hasil kegiatan identifikasi dan analisis masalah bekerjasama dengan teman sejawat dan supervisor, rancangan perbaikan pembelajaran sesuai dengan tujuan perbaikan yang telah ditetapkan selanjutnya dilakukan. Hasil tersebut dijadikan rujukan untuk melaksanakan pembelajaran selanjutnya pada pembelajaran IPS dengan materi kepahlawanan dan patriotisme. Rencana pelaksanaan penelitian dijabarkan sebagai berikut.

1. Menetapkan perencanaan, menentukan tujuan pembelajaran dan tujuan perbaikan pembelajaran.

2. Merancang lembar observasi dan menyampaikan materi tindak lanjut.

3. Menyusun kegiatan yang terdiri dari (1) Memilih bahan yang relevan untuk perbaikan, (2) Menentukan langkah pembelajaran (kegiatan awal, kegiatan inti, kegiatan akhir), (3) Memilih metode pembelajaran, (4) Memilih alat peraga atau media yang sesuai dengan materi pembelajaran, (5) Menyusun alat evaluasi untuk mencapai tujuan perbaikan.

Adapun jadwal pelaksanaan perbaikan pembelajaran disajikan pada Tabel 1 berikut.

Tabel 1. Jadwal Pelaksanaan Penelitian

\begin{tabular}{llcl}
\hline No. & Hari/ Tanggal & Siklus & Materi \\
\hline 1. & Rabu, 08 Agustus & I & $\begin{array}{l}\text { Menjelaskan keteladanan pahlawan } \\
\text { khususnya pahlawan dilingkungan sekitar } \\
2018\end{array}$ \\
2. & Senin, 20 Agustus & II & $\begin{array}{l}\text { Mencoba melakukan diskusi tentang } \\
\text { keteladanan pahlawan dan menyebutkan } \\
\end{array}$ \\
& & \begin{tabular}{l} 
pahlawan yang ada di lingkungan sekitar \\
\hline
\end{tabular}
\end{tabular}


Penelitian ini dilaksanakan dalam dua siklus, dimana sekenario pembelajaran antara siklus I dan II terdapat kesinambungan yang baik.

Pengamatan dan Pengumpulan Data

Data hasil pelaksanaan proses pembelajaran siklus I dan siklus II dilakukan oleh observer menggunakan lembar observasi untuk mengidentifikasi hambatan selama proses pembelajaran.

Refleksi

Refleksi dilakukan berdasarkan hasil diskusi dengan teman sejawat setelah proses perbaikan pembelajaran di setiap siklus.

\section{Instrumen Penelitian}

Data hasil belajar siswa dikumpulan menggunakan instrumen tes, sedangkan data keterlaksanaan pembelajaran dikumpulkan menggunakan lembar observasi.

Penelitian dianggap berhasil jika persentase ketutntasan klasikal siswa $\geq 80 \%$. Ketuntasan klasikal siswa dihitung menggunakan persamaan $[K K=(X / Z) 100 \%]$, di mana $\mathrm{KK}=$ ketuntasan klasikal; $X=$ jumlah siswa yang memperoleh nilai $\geq 7,0$; dan $Z=$ jumlah siswa yang mengikuti tes.

\section{HASIL DAN PEMBAHASAN}

Berdasarkan hasil penelitian yang dilakukan di SDN 2 Sandik Kec. Batulayar Kab. Lombok Barat, maka diperoleh data yang menunjukan aktivitas siswa dalam proses pembelajaran. Selain itu terdapat beberapa hasil pembelajaran yang diperoleh setelah penelitian. Adapun hasil dari penelitian siklus I mata pelajaran IPS di SDN 2 Sandik Kec. Batulayar Kab. Lombok Barat disajikan secara singkat pada Tabel 2 berikut.

Tabel 2. Hasil penelitian siklus I

\begin{tabular}{lll}
\hline Kategori & Jumlah Siswa & Persentase $(\%)$ \\
\hline 1. Baik & 4 orang & $4 / 28 \times 100=14,29$ \\
2. Sedang & 2 orang & $6 / 28 \times 100=21,43$ \\
3. Kurang & 18 orang & $18 / 28 \times 100=64,29$ \\
\hline
\end{tabular}

Berdasarkan Tabel 2 diketahui bahwa nilai yang berkategori baik mencapai $14,29 \%$. Itu artinya sebagian kecil pada siklus I sudah lebih meningkat dari pada sebelum adanya perbaikan pembelajaran. Meskipun demikian, siswa yang berkategori kurang masih dalam poses terbanyak yaitu sebesar 64,29 \% dan yang berkategori sedang sebanyak $21,43 \%$. Itu akhirnya pada siklus ke II jumlah siswa yang berkategori sedang dan kurang harus mengalami penurunan.

Beberapa faktor yang menyebabkan hasil tersebut berdasarkan diskusi (refleksi) teman sejawat/observer) ditemukan beberapa penyebab, antara lain (1) Guru terlalu cepat dalam mencapaikan pembelajaran, (2) Guru kurang menguasai dalam penggunaan alat peraga, (3) Guru kurang menyampaikan tujuan pembelajaran, (4) Guru kurang memberikan penguatan kepada siswa, (5) Tidak adanya diskusi antara siswa dan guru. Hasil refleksi tersebut selanjutnya dijadiakan acuan untuk perbaikan pada siklus II. Hasil belajar siswa pada siklus II secara singkat disajikan pada Tabel 3 berikut. 
Tabel 3. Hasil penelitian siklus I

\begin{tabular}{lll}
\hline Kategori & Jumlah Siswa & Persentase $(\%)$ \\
\hline 1. Baik & 22 orang & $26 / 28 \times 100=92,86$ \\
2. Sedang & 2 orang & $2 / 28 \times 100=7,14$ \\
3. Kurang & - & - \\
\hline
\end{tabular}

Berdasarkan Tabel 3, tampak jelas bahwa nilai yang berkategori baik jauh sangat lebih banyak dan mengalami kenaikan prestasi yang sangat signifikan yaitu mencapai $92,86 \%$. Itu artinya pada siklus ke II sudah menunjukan tingkat keberhasilan proses pembelajaran yang sesuai dengan apa yang diharapkan, sedangkan siswa yang mendapatkan kategori sedang terdapat 7,14\%. Hal ini jelas terliha bahwa prestasi siswa mengalami kenaikan yang cukup pesat.

Berdasarkan temuan data yang diperoleh dari proses perbaikan pembelajaran pada mata pelajara IPS terhadap siswa kelas IV SDN 2 Sandik Kec. Batulayar Kab. Lombok Barat yang sudah dilaksanakan diketahui bahwa ada perubahan belajar siswa yang signifikan dari perkembangan siswa dengan adanya upaya dan desain serta metode pembelajaran yang diupayakan pada setiap siklus pembelajaran. Perbandingan hasil belajar siswa pada setiap siklus disajikan pada Tabel 4 berikut. Tabel 4. Perbandingan hasil belajar siswa

\begin{tabular}{llllll}
\hline \multirow{2}{*}{ No } & \multirow{2}{*}{ Indikator Nilai kognitif } & \multicolumn{2}{c}{ Jumlah Anak } & \multicolumn{2}{c}{ Ketuntasan klasikal (\%) } \\
\cline { 3 - 6 } & Siklus I & Siklus II & Siklus 1 & Siklus II \\
\hline 2 & Baik & 4 & 22 & 14,29 & 92,86 \\
3 & Cukup & 2 & 2 & 21,43 & 7,14 \\
4 & Kurang & 18 & - & 64,29 & 0 \\
\hline & Jumlah & 24 & 24 & 100 & 100 \\
\hline
\end{tabular}

Berdasarkan Tabel 4, diketahui bahwa pelaksanaan proses pembelajaran yang telah dilaksanakan pada Mata Pelajaran IPS menggunakan penguatan verbal dan non-verbal dinyatakan dapat meningkatkan hasil belajar siswa pada materi kepahlawanan dan patriotisme di lingkungan sekitar.

\section{KESIMPULAN}

Berdasarkan hasil penelitian, maka dapat ditarik kesimpulan bahwa pemberian penguatan verbal dan non-verbal pada Mata Pelajaran IPS materi kepahlawanan dan patriotisme di lingkungan sekitar dapat meningkatkan hasil belajar siswa.

\section{SARAN}

Pada proses belajar-mengajar seorang guru harus bisa menyampaikan pembelajaran dengan menarik. Hal ini didasarkan pada siswa yang cenderung malas dan bosan terhadap mata pelajaran IPS, dengan demikian pola diskusi dan penyampaian dengan pola penguatan verbal dan non-verbal dapat disampaikan dengan baik, sehingga hasil pembelajaran yang diperoleh akan menjadi lebih baik. Untuk menjadikan pembelajaran IPS bisa lebih baik disarankan seorang guru bisa melakukan pola pembelajaran yang didesain sedemikian rupa yang mengacu terhadap situasi siswa. Dengan demikian upaya perbaikan pembelajaran akan dapat dilakukan dengan perolehan hasil yang baik dan signifikan. 


\section{DAFTAR PUSTAKA}

Andayani. (2009). Pemantapan Kemampuan Propesional. Jakarta: Universitas Terbuka. Arikunto, S. (2006). Prosedur Penelitian. Jakarta: Rineka Cipta.

Barnawi \& Arifin, M. (2012). Etika dan Profesi Kependidikan. Yogyakarta: Ar-Ruzz.

Bruner, J. (1978). The Process of Educational Technology. Cambridge: Harvard University.

Dimyati, M. (2009). Belajar Dan Pembelajaran. Jakarta. PT. Rineka Cipta.

Farris, P.J. \& Cooper, S.M. (1994). Elementary Social Studies. Dubuque: Brown Communications, Inc.

Newman \& Logan. (1971). Strategy Policy and Central Management.

Sanjaya, W. (2006). Strategi Pembelajaran Berorientasi Standar Proses Pendidikan. Jakarta: Kencana.

Sumantri, M. (2007). Perkembangan Peserta Didik. Jakarta: Universitas Terbuka.

Usman, M., U. (2013). Menjadi Guru Profesional. Bandung: PT Remaja Rosdakarya.

Weton, D. A \& Mallan, J.T. (1988). Children and Their World. Boston: Houghton Mifflin Coy. 